\title{
Erratum to: Further analysis of selection-based instruction, lag reinforcement schedules, and the emergence of topography-based responses to interview questions
}

\author{
J. O’Neill ${ }^{1}$ - A. P. Blowers ${ }^{1}$ - L. Henson ${ }^{2}$. \\ R. A. Rehfeldt ${ }^{1}$
}

Published online: 21 October 2015

(C) Association for Behavior Analysis International 2015

\section{Erratum To: The Analysis of Verbal Behavior, 31, 126-136 \\ DOI: $10.1007 / \mathrm{s} 40616-015-0031-5$}

O’Neill, J., Blowers, A. P., Henson, L., \& Rehfeldt, R. A. (2015). Further analysis of selection-based instruction, lag reinforcement schedules, and the emergence of topography-based responses to interview questions. The Analysis of Verbal Behavior, 31, 126-136.

This article was inadvertently published without an abstract. The abstract and key words appear below.

\begin{abstract}
Three individuals with learning disabilities were exposed to a selection-based instructional protocol that operated on a lag reinforcement schedule intended to teach participants to provide various accurate responses to typical interview questions. At posttest, all participants engaged in higher levels of accurate topography-based responses to interview questions with evidence of generalization and maintenance. The additive effects of the selection-based, audio, and topography-based components of the
\end{abstract}

The online version of the original article can be found at doi:10.1007/s40616-015-0031-5.

\section{J. O’Neill}

joneill@siu.edu

1 Behavior Analysis and Therapy, Rehabilitation Institute, Southern Illinois University Carbondale, Carbondale, IL 62901-4609, USA

2 Evaluation and Developmental Center, Rehabilitation Institute, Southern Illinois University Carbondale, Carbondale, IL 62901-4609, USA 
instructional program were evaluated. Results are discussed in terms of the distinction between selection-based and topography-based responding as well as the multiple control of verbal behavior.

Keywords interview skills training - lag reinforcement schedule $\cdot$ multiple control . selection-based responding topography-based responding 